\title{
Awareness assessment of radiation protection, dose levels and complications of radiation exposure in imaging procedures among radiology residents, undergraduate radiology students, radiologists and technicians.
}

omid azadbakht ( $\square$ omidazadbakht68@gmail.com )

Behbahan University of Medical Sciences https://orcid.org/0000-0003-1272-4121

Seyedeh Leila Dehghani

Behbahan University of Medical Sciences

mohsen shafiee

Abadan University of Medical Sciences

Parsa faghani scandarkolaei

Behbahan University of Medical Sciences

Amirmasoud asadi

Behbahan University of Medical Sciences

Maryam arshadi

Behbahan University of Medical Sciences

Sahar mohammadjani

Behbahan University of Medical Sciences

Pariya hosseini

Behbahan University of Medical Sciences

Zari Dehnavi

Behbahan University of Medical Sciences

Research article

Keywords: Knowledge, Radiation, Dose Assessment, Protection

Posted Date: July 27th, 2020

DOI: https://doi.org/10.21203/rs.3.rs-18369/v2

License: (c) (i) This work is licensed under a Creative Commons Attribution 4.0 International License.

Read Full License 


\section{Abstract}

Background: Identifying the level of radiology students and staffs's awareness of their knowledge of radiation risks and radiation protection and their understanding of radiation dose levels in medical imaging procedures will help global and national lawmakers adjust laws according to the recognized need in studies. The significance of this study is further enhanced when it is considered a lack of radiation awareness may increase the risk of radiation damage to themselves and patients.

Method: This Crossectional study is done on 180 participants, including 62 participants were students (radiology residents and technologists), and 118 participants were radiology staff (radiologists and radiographers). For measuring the awareness of participants, a prepared questionnaire which had a total of 22 questions. The poll was divided into three sections of which: Demographics data, Radiation protection awareness, and knowledge of radiologists about dose assessment. The questionnaire reliability was assessed in terms of internal consistency utilizing the Cronbach's alpha (0.85_). A P-value of less than 0.05 was set a threshold for statistical sig-nuisance. Statistical analysis was carried out using software SPSS version 22.

Result: Most students believed that 1-year-old girls had the most sensitivity to radiation, while most staff found that radiation risk was unrelated to age and sex. Both staff and students found that crews working in nuclear medicine departments were more exposed to radiation (the majority). Most students and faculty also chose breast tissue as the most sensitive organ against radiation. It should be noted that among the staff responses, a significant number of bones were also selected. In general, students and staff did not have sufficient information about radiation-related illnesses. Approximately 82 percent of students chose a dose of Lumbar X-ray exams between 1 and 50 times the PA chest, and only 9 percent answered the question correctly (100-50 times). However, $27 \%$ of employees chose the correct answer. Students on the average dose of mammography had more choice (1-10 times) of a PA chest test, while staff preferred 100-500. (Both groups did not perform well in this question). The crew performed better on the dose resulting from a PET-CT test as well as the dose estimate from a nuclear medicine heart scan, and selected $36 \%$ correct response (more than 500 times the PA chest), while students had a lower rating (1-10 times) than others.

Conclusion: In self-reported; most students and staffs believed that they had a suitable or sufficient level of awareness of ionizing radiation. Overall, $45 \%$ of students and staff rarely had any training or retraining (37\%). Radiology students had a better level of knowledge about radiation protection than team, while team had better estimates in discussing dose assessment. In general, students and staff did not have sufficient information about radiation-related illnesses. Students and staff had accurate estimates of the dose received in a PA chest and the average dose of background radiation. Both groups had little information on mammography, but had good knowledge of ultrasound, MRI, and CT scans. In general, staff and students had a good understanding of nuclear medicine dose assessment.

\section{Background}


Radiographic tools has been one of the most practical instruments in the hospitals, which is utilizable in the diagnostic imaging procedures. The ionizing radiation process occurs in radiographic instruments. Today, the interpretation of radiographic images is one of the most important and practical tools in the diagnosis of diseases by the treatment team. In the early years, of using radiology, Simple radiography was the only eligible image available, which is usually the Primary key by doctors due to its great convenience, high speed "procedures," and relatively low expenditure. For illustration, using computer tomography (CT), which has more radiation exposure than conventional radiography, has increased effectively over 30 recent years. Although it contains abound $50 \%$ of the total radiation burden(1-3). However, CT scans play an important role in the medical field; it causes some concerns about the dangers of cancer. In the science of physics, ionizing radiation is radiation that has sufficient energy to separate an electron from an atom or molecule; In scientific terms, it is called ionization. Researches have recognized significant numbers of worrying effects of radiation which are effective in causing cancer. According to study by Choudik and assistants, there is a possibility of disorders such as goiter, lung and breast cancer, cataract, and leukemia, even in a low-level dose of radiation(4). It is considerable to say that ionizing radiation is able to $51 \%$ increase the probability of cancer, addition, affect other generations just by destroying and damaging DNA. As well as Radiation causes infertility. X-Ray causes slower movements in sperms or standing and death of them in males while females, considering the measure of dose radiation. How much follicles are near to their maturing level, it causes temporary or permanent Infertility. Surveys indicate that receiving every $20 \mathrm{mSv}$, increase the rate of cancers' mortality with the inherited foreground from $25 \%$ to $25.5 \%$ (5). Whereas, a fetus is the most sensitive member of the population against radiation; according to the statement of control and preventing disease centers "exposure to the radiation" especially during the second to fifteenth weeks of pregnancy can effectuate irreversible effects such as: sorts of the raucous, unnatural function of heart and brain, and lack of growth (6). full awareness of radiation protection issues and a proper knowledge of the radiation doses delivered by the various imaging modalities are essential because they deliver various doses (7). A general principle of radiation protection is based on three principles: justification, optimization (as low as reasonably achievable (ALARA)), and dose limitation. This is the foundation of radiation protection strategies. The main principles for radiation protection are time, distance, and shielding, 24 which should be carefully controlled(Statkiewicz-Sherer MA, Visconti PJ, Ritenour ER, Haynes K. Radiation protection in medical radiography. 6 th ed. St. Louis: Mosby; 2018 .) $(8,9)$. If an equal measure of radiation reaches each organ of the body, the most dangerous is for particular organs such as the thyroid gland, marrow, and genitals, which are called critical organs. Boshang explains that the most specific factors in protection against radiation are: 1- raising the distance 2- decreasing the time 3 - using the guided shields (10). Several articles have detected scarce radiation knowledge and unawareness of referral guidelines among clinicians $(11,12)$. By considering the third factor and also improve the awareness of staff for using leaden shields such as thyroid and gonad shields, we can prevent the injuries to the mentioned critical organs. An overall review of the previous study, indicates that radiologists and technologists who are employed in different sections have inadequate information about ionizing beams, or they underestimate its harms (13-16). All the same, another study claims that reducing the dose level in X-Ray examinations is possible if imaging center staff get appropriate training (17). Today, by spreading information, 
clienteles of imaging centers inquire about potential perils of "imaging procedures." (one of every four patients or $25.3 \%$ ) (18), whereas studies have reported the lack of ability to answer correctly to common questions of patients $(19,20)$. On the other hand, As shown by several authors, this increasing use of medical radiation can be partly explained by the inaccurate and often inadequate knowledge among professionals about radiation protection issues and radiation doses of commonly performed imaging procedures $(16,21,22)$. Despite not giving correct information to patients which is inverse to professional and ethical principles, the awareness of ionizing radiation dangers amongst medical staff in imaging centers is essential to plan for accomplishing diagnostic procedures of disease; moreover, it correlates with improving the protection against radiation which is all the primary purpose of the forwarding study. In Iran, there is little information about radiation protection among professional staff and students. The aims of this study were: 1) awareness assessment of radiation protection among radiology students and radiology staff in various imaging processes, including simple graphics and CT scans, etc., in accordance with international principles of radiation protection, 2) awareness assessment of standard dose and the resulting risks among radiology students and radiology staff in various imaging processes 3 ) awareness assessment of the risks of uncontrolled doses on patients and staff among radiology students and radiology staff in various imaging processes 4) The impact of academic and in-service training on radiology students and radiology staff.

\section{Methods}

\subsection{Data collection:}

This crossectional study is done in seven populous provinces of IRAN (Through random cluster sampling, seven provinces from different regions of the country were selected), including Tehran, Mashhad, Fars, Khuzestan, Mazandaran, Kerman, and Hormozgan, in the span two years. Overall this essay involves 180 participants including radiology residents, undergraduate radiology students, radiologists and, radiographer. Among the participants in the case, 62 participants were students (radiology residents and undergraduate radiology students), and 118 participants were radiology staff (radiologists and radiographers). Moreover, radiology students who have passed the protection course were able to join the survey.

The total number of distributed survey is 200 and response rate is $90 \%$.

For measuring the awareness of participants, a prepared questionnaire which had a total of 22 questions, and its validity has been checked was used. The survey was divided into three sections of which: Demographics data 
(Questions in this part consist of: age, gender, work experience and Positioning of the person (student, staff)).

Furthermore, It has requested to everyone that they mention to their knowledge about the dangers of ionizing radiation and have they ever pass any training or reeducated course for radiation protection.

And Radiation protection awareness (Questions in this part have assessed in 7 categories: 1- necessity of inform patients against dangers of ionizing radiation 2- sensitivity of people against radiation that it has divided into four groups and has questioned. 3- Assessing information about an expert who is legally responsible for unreasonable exposures to patients. 4- Assessing awareness of an expert who has the most contact with radiation. 5- Assessing information about the sensitivity of different tissues against radiation. 6- Be aware of probable disease from pollution. 7-Be mindful of dose optimization). And Assessing radiation dose levels (This part has nine questions which they investigate the knowledge of radiologists about dose levels. Furthermore, in questions107 2 to 9 for the purpose of assessing108 radiation 109 dose level, participants are asked to estimate other requested doses by taking the dose 110 of the chest X-Ray (PA) as a reference.

Mentioned questions were asked111 followed: 1 - the average dose of chest X-Ray by msv112 2- the average dose of backgrounds beams in IRAN.3- lumbar spine X-Ray dose. 4-mammography dose 5- chest CT does 6- pelvic magnetic resonance imaging (MRI) dose 7- whole body and PET-CT dose 8- abdominal

ultrasound dose 9- myocardial scintigraphy dose in nuclear medicine by using ${ }^{99 \mathrm{~m}} \mathrm{Tc}$-sestamibi).

\subsection{Statistical analysis:}

A descriptive analysis of the sample was performed. Categorical variables were expressed as percentages, and continuous variables as mean and standard deviation, respectively. The total questionnaire score and the two subscales (Radiation Protection and Dose Assessment) were expressed as median and interquartile ranges (IQR) and displayed on box-plot diagrams. The score differences related to three questionnaire sections among the two groups (radiology Staff and radiography students) were evaluated using the t-test. The questionnaire reliability was assessed in terms of internal consistency utilizing the Cronbach's alpha (0.85_). A P-value of less than 0.05 was set as a threshold for statistical sig-nuisance. Statistical analysis was carried out using software SPSS version 22.

\section{Results}

Table 1 demonstrate that the demographics of participants consider their age and gender, the knowledge of radiation protection in 4 levels (excellent, good, sufficient, and insufficient) and relative trainings. All 180 participants completed the questionnaire. The average age for radiology residents, and radiography staff reported $22.5,35.6$ years old, respectively (t-test $p<0.05$ ). Radiology students and radiography staff constitute $45.5 \%$ and $34.6 \%$ of males participants and $55.5 \%$ and $65.5 \%$ of females respectively in this 
survey (chi-square test, $\mathrm{p}>0.05)$. The questionnaire have acceptable internal reliability $\left(\mathrm{a}=0.780 ; \mathrm{Cl}_{95}\right.$ $0.762-0.852$ ). The quantity of consistency in the internal reliability of the questionnaire was also investigated amongst participants. Cronbach's a coefficients were $0.760\left(\mathrm{Cl}_{95} 0.746-0.796\right), 0.727\left(\mathrm{Cl}_{95}\right.$ $0.688-0.744)$ and $0.797\left(\mathrm{Cl}_{95} 0.696-0.835\right)$, respectively. Regarding perceived knowledge in participants, it has shown that radiology staff had the most information in good level ( $40.5 \%$ ) compared to radiology students ( $36.1 \%$ ); moreover, their knowledge in the excellent level was by far the lowest amount $6.6 \%$ for radiology students and $10.3 \%$ for radiology staff. Fact, $41 \%$ of radiology residents had sufficient information (Fisher's exact test, $\mathrm{p}<0.05$ ).

Fig1 indicates the total questionnaire scores in different charts. All there tables give information for radiology students and radiology staff. Chart $A$ illustrates the scores of radiation protection knowledge. In which radiology students got the score between 3 to 4 out of 5 while radiology staff got the score, approximately between 1.8 to 2.8 out of 4 (Kruskal-Wallis test $p<0.001$ ). Chart B shows the amount of dose level assessment. The count of dose level assessment reported around 4.5 out of 8.5 for radiology staff while for radiology students. It was approximately 2.5 out of the maximum of 8 . (Kruskal-Wallis test, $p<0.001)$. Regarding chart $C$, the overall knowledge among both groups was as followed: about 7.7 out of more than 12.5 and 5.7 out of 11.7 for radiology staff and radiology students respectively, (KruskalWallis test, $p<0.001$ ).

\section{1. Radiation protection knowledge:}

Fig 2 gives a describes of the statistics of radiology staff and radiology students' education to survey questions about general radiation protection issues. Considering to chart 1 , shows that the majority numbers of both radiology students $(79.1 \%$ ) and radiology staff (about $87 \%$ ) were aware of the necessity to inform patients about the dangers of radiation exposure. As can be seen, the highest percentage about the responses to the question of "which patients have the most sensitivity to ionizing radiation?" was reported for radiology students (slightly less than $50 \%$ ) as one-year-old girl while around $45 \%$ of radiology staff answered that the risk of radiation damage does not depend on age or sex.

A high rate of radiology students and radiology staff have correctly answer that all items in the bar chart 3 are responsible for unnecessary patient exposure and lack of optimization.

Considerably about $6 \%$ of both groups (lowest percent) responded that only radiological staffs are responsible for this matter $(p<0.05)$.

Interventional radiologists and cardiologists accounted for the second-highest amount of exposed professionals, at the same time, nuclear medicine has answered as the most exposed category with the 
percentage of approximately 38 and just above 50 for radiology students and radiology staff, respectively. About $64 \%$ of radiology students and $40 \%$ of radiology staff considered breast as the most sensitive tissue.

Regarding the question about " which of the following disease may be a result of stochastic radiation damage? " the percentages of those who answered all times ( dermatitis, leukemia, alopecia, and cataract ) were the highest ratio slightly more than $40 \%$ and around $50 \%$ for radiology students and staff respectively. The final question, which is described in bar chart number 7 , is about the meaning of dose optimization. As can be seen, the above rates of answers were reported for radiology staff (around $60 \%$ ). All the same, the percentage for radiology students who answered all mentioned items in the chart were the same as their answer that was said, in radiological tests $(p<0.05)$.

\section{2. Knowledge of recommended radiation dose levels for the main imaging procedures:}

Table 2 gives a breakdown of the percentage of answers to the questions about the dose of natural background, commonly performed imaging examinations given by radiology students and staff.

The two exanimated groups estimated the average dose for a PA chest radiograph, $0.01-0.1 \mathrm{mSv}$ in this way: $29 \%$ and $49.5 \%$ of radiology students and radiology staff, respectively (Fisher's exact test, $p<$ $0.05)$.

$6.6 \%$ of radiography students and significantly less than that, $2.9 \%$ of radiology staff in Iran answer the average dose of the natural background radiation correctly.

Regarding the average dose due to a lumbar X-Ray examination, $9.8 \%$ of radiography students and around three times more than that, $27.7 \%$ of radiology staff gave the correct dose value.

The average dose due to mammography was known by $19.7 \%$ of radiography students and $17.8 \%$ of radiology staff; all the same 10.1 in total consider mammography as a radiation-free procedure should be a matter of concern ( $8.1 \%$ of radiography students and $2 \%$ of radiology staff).

The next figure shows the average dose because of the non-contrast chest CT examinations in which it was correctly estimated by $45.9 \%$ and slightly less $45.1 \%$ for radiography students and radiology residents, respectively. Considerably for radiography students and radiology staff, those who answered that CT involves no radiation exposure, the ratio is $0 \%$ for the former survey respondents and $1 \%$ for the later. The MRI examination was correctly identified as radiation-free by $62.3 \%$ of radiography students and significantly $88.5 \%$ of radiology staff. As for nuclear medicine procedures, the correct estimation ratio for the radiation dose of PET-CT examinations was $20 \%$ of radiography students and $36.7 \%$ of radiology staff ; $(p<0.05)$; however the average dose due to myocardial scintigraphy has estimated by $16.7 \%$ of the former respondents and $55.7 \%$ for the later; $(p<0.05)$. Furthermore, as can be seen, $3.4 \%$ of radiology students about PET-CT examinations and exactly half of that $(1.7 \%)$ for myocardial 
scintigraphy thought that these examinations are not associated with radiation exposure, this ratio for radiology staff was $2 \%$ for the former analysis and $0 \%$ for the later.

Table 2 overall distributions of answers to questions about the dose of natural background radiation and commonly performed imaging examinations given by Radiology staff and radiography students. Values are expressed in terms of equivalent number of chest radiographs. Correct answers are highlighted in shaded bold.

\section{Discussion}

this study found that most staff and students believe that awareness of the dangers of radiation to patients is essential. It also turned out that doctors were not aware of the dangers of radiation. This result was contrary to the results obtained from the study of Fatahi, et al. Amirzadeh et al., and Borhani et al. It has been mentioned in studies conducted by Fatahi, et al, Amirzadeh et al, and Borhani et al, a statistically significant difference was observed in the protection knowledge and performance score means of radiographers with an associate's degree and those holding a bachelor's, indicating protection knowledge and performance improved as individuals' level of education was higher.(23-25) Studies Dunlap et al. and Shiralkar et al. also found that physicians require radiation training (1-3). On the other hand, studies Rostami et al., Masoumi et al., and Briggs-kamara et al. indicated that the knowledge of radiation experts was also low (26-28). based on our study and confirmation of studies Briggs-kamara et al. and Ria et al., it was found that patients' awareness was deficient $(18,19,26,29,30)$, It should be noted that in our study, most radiation students and staff thought they were well aware and did not need to undergo training. However, in studies Masoumi et al. and Rostamzadeh et al., it was found that training reduces radiation risks and increases radiation awareness $(27,31)$. Several cases raise the level of radiation knowledge in staffs, patients, and physicians. Continuous beam training increases radiation safety and reduces fear of radiation $(27,31,32)$, as well as determining radiation levels and dose level references for each region (17) and monitoring personnel radiation measures are two other effective strategies (33). In our study, it was clearly demonstrated that the dose received in nuclear medicine tests (more than 500 times that of Chest PA) increased the risk of cancer in younger people, especially in vulnerable tissues. Research by Huang et al. have also pointed out that although PET / CT facilitates the diagnosis, it also increases the risk of cancer. Therefore, these examinations should be justified, and appropriate measures should be taken to reduce the dose received (34). More than $50 \%$ of our subjects have erroneous dose assessment data on CT Scans, which has been found in Lee Cl et al. (13), And in Rostamzadeh et al. (31), Which may imply that ionizing imaging may give physicians very high precision, still, physicians Neither do they give patients information about the risk of a CT scan nor are they able to estimate the exact dose of imaging for specific anatomical areas. A study by Zhou et al. Also acknowledged that about $55 \%$ did not estimate the radiation dose level for correct radiology tests, and. 
Also, about $60 \%$ underestimated the risk of cancer from the Abdominal CT scan (lack of radiation knowledge) (35). In a study by Zhou et al., It was found that about $11 \%$ and $25 \%$ believed that MRI and ultrasound had ionizing radiation (lack of radiation knowledge), in comparison, about $10 \%$ of the subjects considered radiation knowledge to be irrelevant. And it should be noted that this study clearly (about $40 \%$ ) among radiology students and (10\%) among radiology staff considered MRI tests with ionizing radiation (35). A study by Faggioni et al. found that people with less radiation knowledge had higher selfesteem. This issue led to poor self-esteem among medical students, which may be one of the psychological factors for inattention to learn about the subject of radiation knowledge (36). L.Borgen and his colleagues have found that radiology experts and residents have more radiation and shielding information from physicians due to the specialized nature of their units, which confirms our results(19). In their study, Dehghani and colleagues found that only $6 \%$ of the subjects were well aware that this result is very similar to our results, although it should be noted that our statistical population was much larger (37). In the our study, there was a significant relationship between the level of previous knowledge of students and staffs with radiation protection, which results were consistent with results of Shabani, et al. study(38). On the other hand, in our study and Shabani, et al., there was no significant relationship between gender of participants and radiation protection, which was contrary to results of Fatahi - Asl, et al. study $(25,38)$. Limitations of the study include uncooperativeness on the part of some radiographers in filling out the questionnaires and a need to conduct the study on a larger scale. Considering the results and the significance of protection against ionizing radiation, holding more workshops, short-term training courses, preparation and distribution of posters and pamphlets on the effects of radiation on the body and protection and safety against ionizing radiation are recommended to raise staff and patients' knowledge and awareness levels. In addition, more inspection and supervision by health physics authorities seems in order..According to the results of this study, it is suggested that regular training courses on radiation protection should be held for all employees using radiation.

\section{Conclusion}

Most students and staff believed that they had an excellent or sufficient level of awareness of ionizing radiation. Overall, $45 \%$ of students and staff rarely had any training or retraining (37\%). Radiology students had a better level of knowledge about radiation protection than team, while team had better estimates in discussing dose assessment. In general, students and staff did not have sufficient information about radiation-related illnesses. Students and staff had accurate estimates of the dose received in a PA chest and the average dose of background radiation. Both groups had little information on mammography, but had good knowledge of ultrasound, MRI, and CT scans. In general, staff and students had a good understanding of nuclear medicine dose assessment. (Staff performed better)

\section{Abbreviations}

CT: computer tomography

PA: posterior-anterior 
MRI: magnetic resonance imaging

PET: positron emission tomography

IQR: interquartile ranges

\section{Declarations}

\section{Ethics approval and consent to participate:}

This study was reviewed by the Ethics Committee of Behbahan School of Medical Sciences. Therefore the Ethics Committee of Behbahan Paramedical School stated that this study does not require ethical approval.Informed consent was obtained from participants information. The results of this study were provided to the participants.

\section{Consent for publication:}

All participants included in this research gave written informed consent to publish the data contained within this study. In this study, informed consent was obtained from all participants. The participants was illiterate when consent for publication was requested, written informed consent for the publication of this data was given.

\section{Availability of data and material:}

The datasets used and/or analyzed during the current study available from the corresponding author on reasonable request.

\section{Competing Interests:}

Article Title: Awareness assessment of radiation protection, dose levels and complications of radiation exposure in imaging procedures among radiology residents, undergraduate radiology students, radiologists and technicians.

Author(s): Omid Azadbakht MS1, Seyedeh Leila Dehghani PHD2, Mohsen shafiee MSN3, Parsa faghani scandarkolaei BS4, Amirmasoud asadi BS4, Maryam arshadi BS4, Sahar mohammadjani BS4, Pariya hosseini BS4, Zari Dehnavi MS. 
We declare that we have no significant competing financial, professional, or personal interests that might have influenced the performance or presentation of the work described in this manuscript.

We have described us potential competing financial, professional, and/or personal interests in the space.

\section{Funding:}

No funding was obtained for this study.

\section{Authors' contributions:}

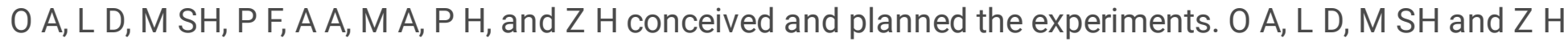
carried out the experiments. $O A, L D$, and $M S H$ planned and carried out the simulations. $P F, A A, M A, P$ $\mathrm{H}$, and $\mathrm{Z} \mathrm{H}$ participated in the gathering. $O \mathrm{~A}, \mathrm{~L} D, M S H$ and $\mathrm{Z} \mathrm{H}$ contributed to sample preparation. $\mathrm{OA}, \mathrm{L}$ $\mathrm{D}, \mathrm{M} \mathrm{SH}$ and $\mathrm{Z} \mathrm{H}$ contributed to the interpretation of the results. $\mathrm{O} \mathrm{A}$ took the lead in writing the manuscript. All authors provided critical feedback and helped shape the research, analysis and manuscript. All authors read and approved the final manuscript.

\section{Acknowledgment:}

We would like to extend our thanks to the students and staff which without their kind cooperation this study would not have been feasible.

\section{References}

1. Shiralkar S, Rennie A, Snow M, Galland R, Lewis M, Gower-Thomas K. Doctors' knowledge of radiation exposure: questionnaire study. Bmj. 2003;327(7411):371-2.

2. Mettler Jr FA, Bhargavan M, Faulkner K, Gilley DB, Gray JE, Ibbott GS, et al. Radiologic and nuclear medicine studies in the United States and worldwide: frequency, radiation dose, and comparison with other radiation sources-1950-2007. Radiology. 2009;253(2):520-31.

3. Günalp M, Gülünay B, Polat $O$, Demirkan A, Gürler $S$, Akkaş $M$, et al. lonising radiation awareness among resident doctors, interns, and radiographers in a university hospital emergency department. La radiologia medica. 2014;119(6):440-7.

4. Chodick G, Bekiroglu N, Hauptmann M, Alexander BH, Freedman DM, Doody MM, et al. Risk of cataract after exposure to low doses of ionizing radiation: a 20-year prospective cohort study among 
US radiologic technologists. American journal of epidemiology. 2008;168(6):620-31.

5. Boxall AB, Hardy A, Beulke S, Boucard T, Burgin L, Falloon PD, et al. Impacts of climate change on indirect human exposure to pathogens and chemicals from agriculture. Environmental health perspectives. 2009;117(4):508-14.

6. Nolan CM, Blumberg HM, Taylor Z, Bernardo J. American thoracic society/centers for disease control and prevention/infectious diseases society of America: Controlling tuberculosis in the United States. American Journal of Respiratory and Critical Care Medicine. 2005;172(9):1169.

7. Shaw PV, Croüail P, Paynter $R$, Coeck $M$. Education and training in radiation protection: improving ALARA culture. Journal of Radiological Protection. 2015;35(1):223.

8. Sherer MAS, Visconti PJ, Ritenour ER, Kelli Haynes M. Radiation protection in medical radiography: Elsevier Health Sciences; 2013.

9. Khamtuikrua C, Suksompong S. Awareness about radiation hazards and knowledge about radiation protection among healthcare personnel: A quaternary care academic center-based study. SAGE Open Medicine. 2020;8:2050312120901733.

10. Bushong SC. Radiologic science for technologists-E-book: physics, biology, and protection: Elsevier Health Sciences; 2013.

11. Borgen L, Stranden E, Espeland A. Clinicians' justification of imaging: do radiation issues play a role? Insights into imaging. 2010;1(3):193-200.

12. Bautista AB, Burgos A, Nickel BJ, Yoon JJ, Tilara AA, Amorosa JK. Do clinicians use the American College of Radiology Appropriateness criteria in the management of their patients? American journal of roentgenology. 2009;192(6):1581-5.

13. Lee Cl, Haims AH, Monico EP, Brink JA, Forman HP. Diagnostic CT scans: assessment of patient, physician, and radiologist awareness of radiation dose and possible risks. Radiology. 2004;231(2):393-8.

14. Ramanathan S, Ryan J. Radiation awareness among radiology residents, technologists, fellows and staff: where do we stand? Insights into imaging. 2015;6(1):133-9.

15. Ünal ES, Geliş K, Baykan P. Investigation of awareness levels about the radiation safety of personnel working in the imaging units of the hospitals in Agri, Turkey. Journal of radiation research and applied sciences. 2018;11(2):111-5.

16. Yurt A, Çavuşoğlu B, Günay T. Evaluation of awareness on radiation protection and knowledge about radiological examinations in healthcare professionals who use ionized radiation at work. Molecular imaging and radionuclide therapy. 2014;23(2):48.

17. Rasuli B, Juybari RT, Forouzi M, Ghorbani M. Patient dose measurement in common medical X-ray examinations and propose the first local dose reference levels to diagnostic radiology in Iran. Polish Journal of Medical Physics and Engineering. 2017;23(3):67-71.

18. Ria F, Bergantin A, Vai A, Bonfanti P, Martinotti A, Redaelli I, et al. Awareness of medical radiation exposure among patients: a patient survey as a first step for effective communication of ionizing radiation risks. Physica Medica. 2017;43:57-62. 
19. Borgen L, Stranden E. Radiation knowledge and perception of referral practice among radiologists and radiographers compared with referring clinicians. Insights into imaging. 2014;5(5):635-40.

20. Singh P, Aggarwal S, Kapoor AMS, Kaur R, Kaur A. A prospective study assessing clinicians attitude and knowledge on radiation exposure to patients during radiological investigations. Journal of natural science, biology, and medicine. 2015;6(2):398.

21. Brown $\mathrm{N}$, Jones $\mathrm{L}$. Knowledge of medical imaging radiation dose and risk among doctors. Journal of medical imaging and radiation oncology. 2013;57(1):8-14.

22. Thomas KE, Parnell-Parmley JE, Haidar S, Moineddin R, Charkot E, BenDavid G, et al. Assessment of radiation dose awareness among pediatricians. Pediatric radiology. 2006;36(8):823-32.

23. Amirzadeh F, Tabatabaie S. Study of protection knowledge of technologists in Shiraz hospitals. Iran J Nuclear Med. 2006;13(24):38-44.

24. Borhani P, MOHAMMAD AS. Evaluation of radiology personnel practice of Kerman university of medical sciences hospitals. 2003.

25. Fatahi-AsI J, Tahmasebi M, Karami V. The Protection knowledge and performance of Radiographers in some hospitals of Ahvaz County. Jentashapir J Health Res. 2013;4(5):405-12.

26. Briggs-Kamara MA, Okoye PC, Omubo-Pepple VB. Radiation safety awareness among patients and radiographers in three hospitals in Port Harcourt. Am J Sci Ind Res. 2013;4(1):83-8.

27. Masoumi H, Hasanzadeh H, Jadidi M, Mirmohammadkhani M, Bitarafan-Rajabi A, Abedelahi A, et al. A survey on the radiation protection status among radiology staff. Iranian Journal of Medical Physics. 2018;15(3):176-82.

28. Rostami A, Cheshmyazdan MR, Payande Vafa M, Kia L, Ghoreishi FS. Physicians' Knowledge about Different Radiobiology Aspect and Radiation Dose, Received by Patients in Diagnostic Radiology in 2013. Journal of Payavard Salamat. 2016;10(1):69-81.

29. AS Alahmari M, Sun Z. A systematic review of the efficiency of radiation protection training in raising awareness of medical staff working in catheterisation laboratory. Current Medical Imaging. 2015;11(3):200-6.

30. Awosan K, Ibrahim M, Saidu S, Ma'aji S, Danfulani M, Yunusa E, et al. Knowledge of radiation hazards, radiation protection practices and clinical profile of health workers in a teaching hospital in Northern Nigeria. Journal of clinical and diagnostic research: JCDR. 2016;10(8):LC07.

31. Rostamzadeh A, Farzizadeh M, Fatehi D. Evaluation of the level of protection in Radiology Departments of Kermanshah, Iran. Iranian Journal of Medical Physics. 2015;12(3):200-8.

32. Kiguli-Malwadde E, Matovu PD, Kawooya M, Byanyima R. Radiation safety awareness among radiation workers and clientele at Mulago Hospital, Kampala, Uganda. East and Central African Journal of Surgery. 2006;11(1):49-51.

33. Iortile J, Archibong B, Chelen J. Assessment of the levels of radiation absorbed by radiology personnel in some hospitals in Makurdi metropolis. International Journal of Natural Sciences Research. 2013;1(4):26-9. 
34. Huang B, Law MW-M, Khong P-L. Whole-body PET/CT scanning: estimation of radiation dose and cancer risk. Radiology. 2009;251(1):166-74.

35. Zhou G, Wong D, Nguyen L, Mendelson R. Student and intern awareness of ionising radiation exposure from common diagnostic imaging procedures. Journal of medical imaging and radiation oncology. 2010;54(1):17-23.

36. Faggioni L, Paolicchi F, Bastiani L, Guido D, Caramella D. Awareness of radiation protection and dose levels of imaging procedures among medical students, radiography students, and radiology residents at an academic hospital: results of a comprehensive survey. European Journal of Radiology. 2017;86:135-42.

37. Dehghani A, Ranjbarian M, Mohammadi A, Soleiman-Zade M, Dadashpour-Ahangar A. Radiation safety awareness amongst staff and patients in the hospitals. International journal of occupational hygiene. 2014;6(3):114-9.

38. Shabani F, Hasanzadeh H, Emadi A, Mirmohammadkhani M, Bitarafan-Rajabi A, Abedelahi A, et al. Radiation protection knowledge, attitude, and practice (KAP) in interventional radiology. Oman medical journal. 2018;33(2):141.

\section{Tables}

Table 1 Sample demographics (age, gender, and level of radiation protection awareness and training). $\mathrm{SD}=$ standard deviation. *t-test ${ }^{* *}$ Chi-square test. $\mathrm{P}<0.05$ indicates statistical significance. 


\begin{tabular}{|c|c|c|c|c|}
\hline variable & & $\begin{array}{l}\text { Radiology } \\
\text { students }\end{array}$ & $\begin{array}{l}\text { Radiology } \\
\text { staff }\end{array}$ & P-value \\
\hline Age (mean \pm SD) & & $22.5 \pm 2.8$ & $35.6 \pm 6.8$ & \\
\hline & & & & $<0.05 *$ \\
\hline Gender (\%) & Male & 45.5 & 34.6 & $>0.0 b^{* *}$ \\
\hline & Female & 55.5 & 65.4 & \\
\hline Perceived knowledge & Excellent & 6.6 & 10.3 & $<0.05 * *$ \\
\hline & Good & 36.1 & & \\
\hline & Sufficiont & 11 & 40.5 & \\
\hline & & & 41.4 & \\
\hline & Insufficient & 16.4 & & \\
\hline & & & 7.8 & \\
\hline Training (\%) & Frequently & 17.7 & & $>0.05^{* *}$ \\
\hline & & $152+2>$ & $\frac{16.4}{15.7}$ & \\
\hline & Rarely & 45.2 & 45.7 & \\
\hline & Never & 37.1 & 37.9 & \\
\hline
\end{tabular}

Table 2 overall distributions of answers to questions about the dose of natural background radiation and commonly performed imaging examinations given by Radiology staff and radiography students. Values are expressed in terms of equivalent number of chest radiographs. Correct answers are highlighted in shaded bold.

[Please see the supplementary files section to view Table 2.]

\section{Figures}


A
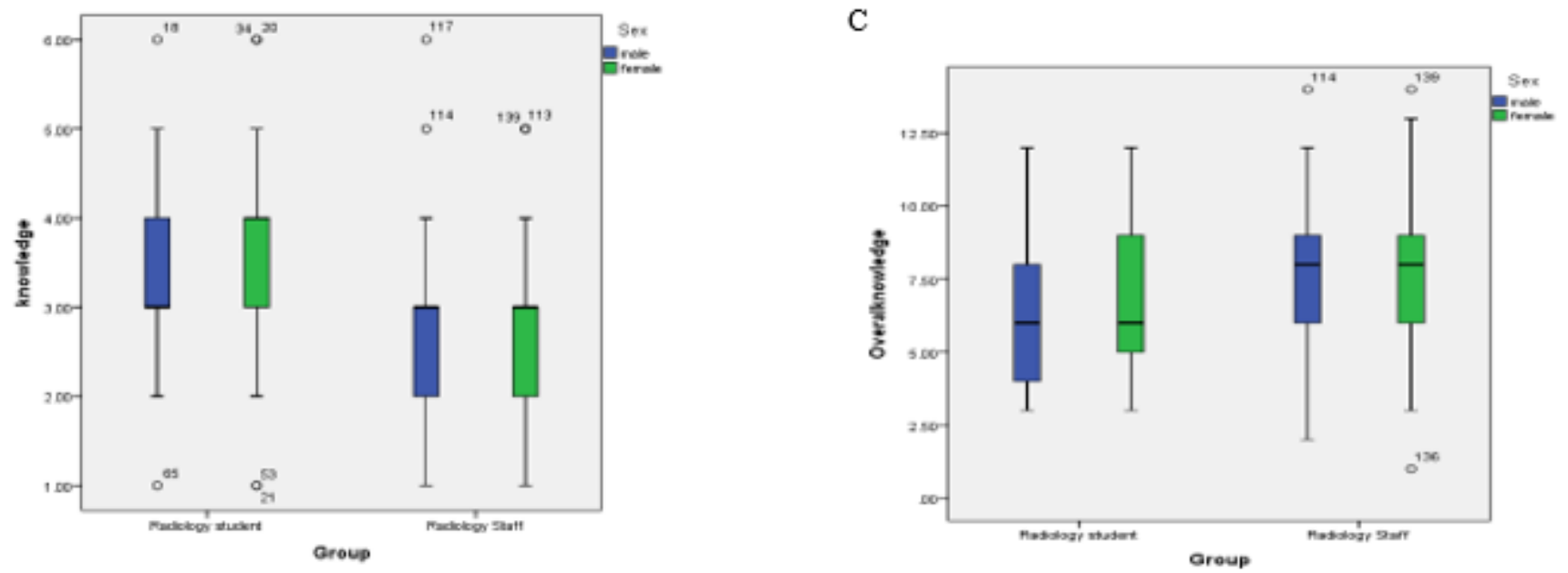

B

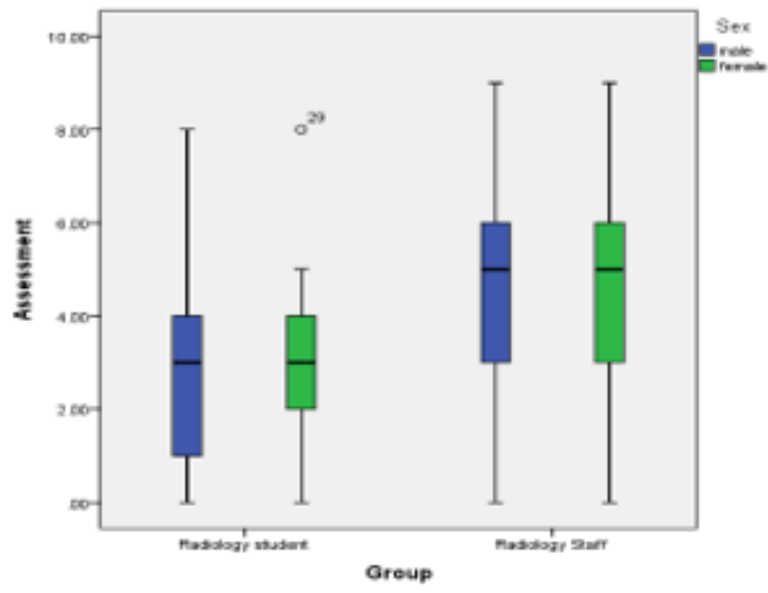

Figure 1

Distribution of scores related to knowledge of radiation protection (a), dose level assessment (b), and overall knowledge (i.e. radiation protection and dose level assessment) among radiology residents, and radiography staff (c). Box plot diagrams show the distribution of median, interquartile range, minimum and maximum values.
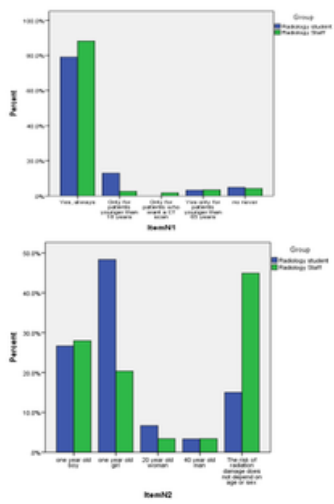

Figure 2
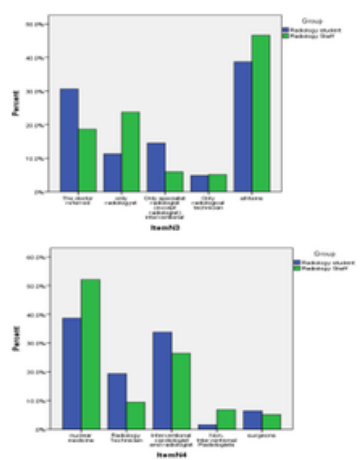
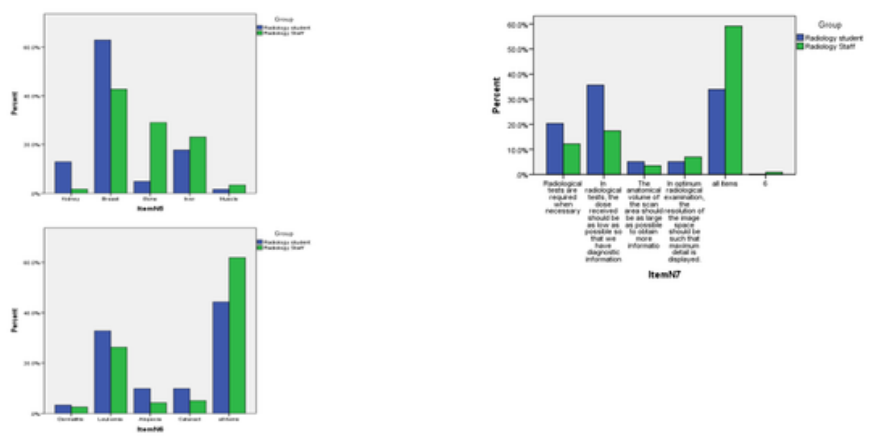
Descriptive statistics of radiology staff and radiography students' answers to survey questions about general radiation protection issues (a, questions from 1 to 4 ; $b$, questions from 5 to 7 of Section 2 of the survey questionnaire). Correct answers are boxed. $I R=$ ionizing radiation

\section{Supplementary Files}

This is a list of supplementary files associated with this preprint. Click to download.

- Table2.docx 